\title{
Aplicação do Design Centrado em Humano para Desenvolvimento de uma Solução de Software baseada em Informações do Tempo e Clima
}

\author{
João M. N. Silva' ${ }^{1}$, Tamires P. Silva ${ }^{1}$, Marcos I. Lima ${ }^{1}$, Ricardo A. C. Souza ${ }^{2}$ \\ ${ }^{1}$ Bacharelado em Ciência da Computação - Universidade Federal Rural de Pernambuco \\ - Rua Dom Manoel de Medeiros s/n - Dois Irmãos - 52.171-900 - Recife - PE - Brasil \\ ${ }^{2}$ Departamento de Computação (DC) - Universidade Federal Rural de Pernambuco \\ (UFRPE) - Recife, PE - Brasil \\ jn.marcosdoutlook.com, tamirespereira6@gmail.com, \\ marcos.inacio.recife@hotmail.com, ricardo.souza@ufrpe.br
}

\begin{abstract}
Incidents caused by precipitation (rains) such as flooding and landslides are recurrent in Brazilian cities. Such events usually result in result in material damage and threaten the lives of people residing in an area of risk. Weather and climate information, when accessed and shared timely through efficient communication channels, can help good decision-making by public agents and the general population. In this scenario, this paper presents an experience report about the application of the HCD (Human-Centered Design) process for the development of a software solution based on the use and exchange of weather and climate information between the public organizations and the population in the context of a Brazilian large city.
\end{abstract}

Resumo. Incidentes causados por precipitações, tais como, alagamentos e desabamentos são recorrentes em cidades brasileiras. Tais eventos geralmente provocam danos materiais e ameaçam a vida de pessoas residentes em área de riscos. Informações do tempo e clima, quando acessadas e compartilhadas tempestivamente por meio de canais de comunicação eficientes, podem vir a auxiliar a boa tomada de decisão pelos agentes públicos e população. Este trabalho apresenta o relato de experiência da aplicação do processo HCD (Human-Centered Design) para desenvolvimento de uma solução de software baseada no uso e troca de informações climatológicas entre organizações públicas e a população no contexto de uma grande cidade brasileira.

\section{Introdução}

A cidade do Recife, capital do estado de Pernambuco, possui um clima tropical úmido caracterizado por dois períodos bem distintos. O primeiro é uma estação de estiagem, de setembro a fevereiro, enquanto a segunda é chuvosa, de março a agosto [Barros e Lombardo, 2013]. Essa situação, aliada com deficiências no planejamento urbano e com características geográficas, como o relevo e altitude, tornam a cidade vulnerável quanto à ocorrência de alagamentos, deslizamento de barreiras e encostas, além de tornar caótica a mobilidade urbana em dias de precipitação (chuva). 
As consequências das chuvas se tornam mais danosas em áreas de riscos, que correspondem a regiões com maior probabilidade de ocorrência de alagamentos, enchentes, desmoronamento de terra ou qualquer outro evento que impacte no bem-estar geral da população.

A Agência Pernambucana de Águas e Clima (APAC) ${ }^{1}$ é a organização pública responsável por monitorar e comunicar informações sobre o clima e tempo do estado de Pernambuco para os mais diversos interessados, tal como a Defesa Civil do município do Recife, organização responsável por atuar na prevenção e reparo de danos causados por eventos naturais, como os causados por chuvas. Melhorar a interação entre a APAC e a Defesa Civil, através da otimização da comunicação de informações do clima e tempo, tende também a beneficiar a própria população, principalmente aquela residente em áreas de riscos. Tal desafio motivou a aplicação do processo HCD (Human-Centered Design) (HCD, 2018) para desenvolvimento de uma solução baseada em software.

Além desta seção introdutória, este artigo está estruturado em mais quatro seções. Na Seção 2 é apresentada a fundamentação teórica que orientou o trabalho. Na Seção 3 é apresentado o relato da execução do processo HCD. Por fim, na Seção 4, são descritas as considerações finais.

\section{Fundamentação Teórica}

Quanto à metodologia de pesquisa, este trabalho pode ser considerado uma pesquisa exploratória, pois permitiu maior familiaridade do pesquisador (grupo de trabalho) com o tema pesquisado e não visa avaliar uma hipótese, mas sim apresentar um relato da experiência realizada.

Quanto ao processo de desenvolvimento da solução, este trabalho baseou-se no Design Centrado em Humano (HCD). O HCD objetiva resolver problemas orientado pela perspectiva humana em todas as etapas do processo. O processo HCD (HCD, 2018) consiste de três fases: Inspiração, Ideação e implementação. Na Inspiração são coletadas histórias e procuradas por oportunidades de inovação (insights) no que é mais relevante para as pessoas, a partir do entendimento das esperanças, dores e necessidades delas. A Ideação consiste em usar a criatividade para geração, refinamento e avaliação de ideias de como explorar os insights obtidos na inspiração. A Implementação consiste em materializar as ideias de solução e avaliar aquela mais promissora a partir do feedback dos interessados.

O processo HCD busca a inovação considerando as necessidades e perspectivas dos usuários finais como direcionador de todas as atividades realizadas, bem como procura envolver tais usuários desde a concepção do produto ou serviço. Por outro lado, os serviços climáticos precisam atender às necessidades, capacidades e estruturas de decisões dos usuários e, portanto, a colaboração de potenciais usuários desde os estágios iniciais do processo de design destes serviços se faz necessária para possibilitar o efetivo uso e apoiar a tomada de decisão no dia-a-dia [Christel et al., 2018].

\footnotetext{
${ }^{1}$ www.apac.pe.gov.br
} 
Entre os trabalhos relacionados estão aqueles que utilizam o processo HCD para desenvolvimento de soluções e outros que propõem soluções baseadas em informações climatológicas. Alguns destes trabalhos são brevemente descritos a seguir.

Fukuzumi et al. (2017) descrevem a aplicação do HCD para desenvolvimento de software com ênfase no aspecto de usabilidade. Para tanto, foram executados os seguintes passos: entendimento da demanda de acordo com a perspectiva dos usuários; atendimento às especificidades da usabilidade não tratadas pela engenharia de software tradicional; e desenvolvimento de protótipos para avaliação da usabilidade do software.

Ribeiro et al. (2018) relatam o uso do conjunto de ferramentas (toolkit) providas pelo HCD para desenvolvimento de um aplicativo de alerta de alagamento para uso em dispositivos móveis. Tais ferramentas foram usadas para auxiliar a execução das etapas do HCD: inspiração, na qual foram coletadas as histórias que inspiraram a equipe, através de pesquisas de campo; ideação, na qual foram identificadas oportunidades e geradas ideias de como explorar tais oportunidades; e implementação, na qual a ideia mais promissora foi materializada e avaliada pelos usuários com o objetivo de aprendizado a partir do feedback obtido.

Hirata et al. (2013) propõem um sistema dinâmico e colaborativo de mapeamento de pontos de alagamentos, a partir de informações georeferenciadas providas pelos usuários através de um aplicativo para dispositivos móveis. Neste trabalho também é usado um sistema colaborativo em que as informações advindas da população ajudam na definição de prioridades e ações a serem realizadas pela Defesa Civil.

Viríssimo et al. (2014) apresentam o sistema NIAGRISK que tem como objetivo o monitoramento ambiental e a gestão e alerta de riscos relacionados a desastres naturais. O NIAGRISK se apresenta como uma ferramenta na qual o enfoque recai sobre o monitoramento dos alertas emitidos, uma vez que o conhecimento para as análises dos riscos está embutido dentro do sistema. Neste trabalho, é usada a ideia de alertas para notificar moradores de áreas de riscos sobre possíveis incidentes naturais.

\section{Execução do Processo HCD}

Nesta seção é apresentada a execução das fases do processo HCD para desenvolvimento de uma solução baseada em software para melhorar a comunicação de informações do clima e tempo entre as organizações públicas e a população em geral.

\subsection{Inspiração}

A etapa de inspiração iniciou com entrevistas não estruturadas com funcionários da APAC para obtenção de maiores informações sobre o trabalho realizado. Os resultados dessas entrevistas foram então consolidados em um Mapa da Empatia (Figura 01) que consiste em uma ferramenta de síntese que descreve o que as pessoas dizem e fazem (say and do), o que elas escutam (hear), pensam e sentem (think and feel) e veem (see), bem como as principais dores (pain) e ganhos (gain). 

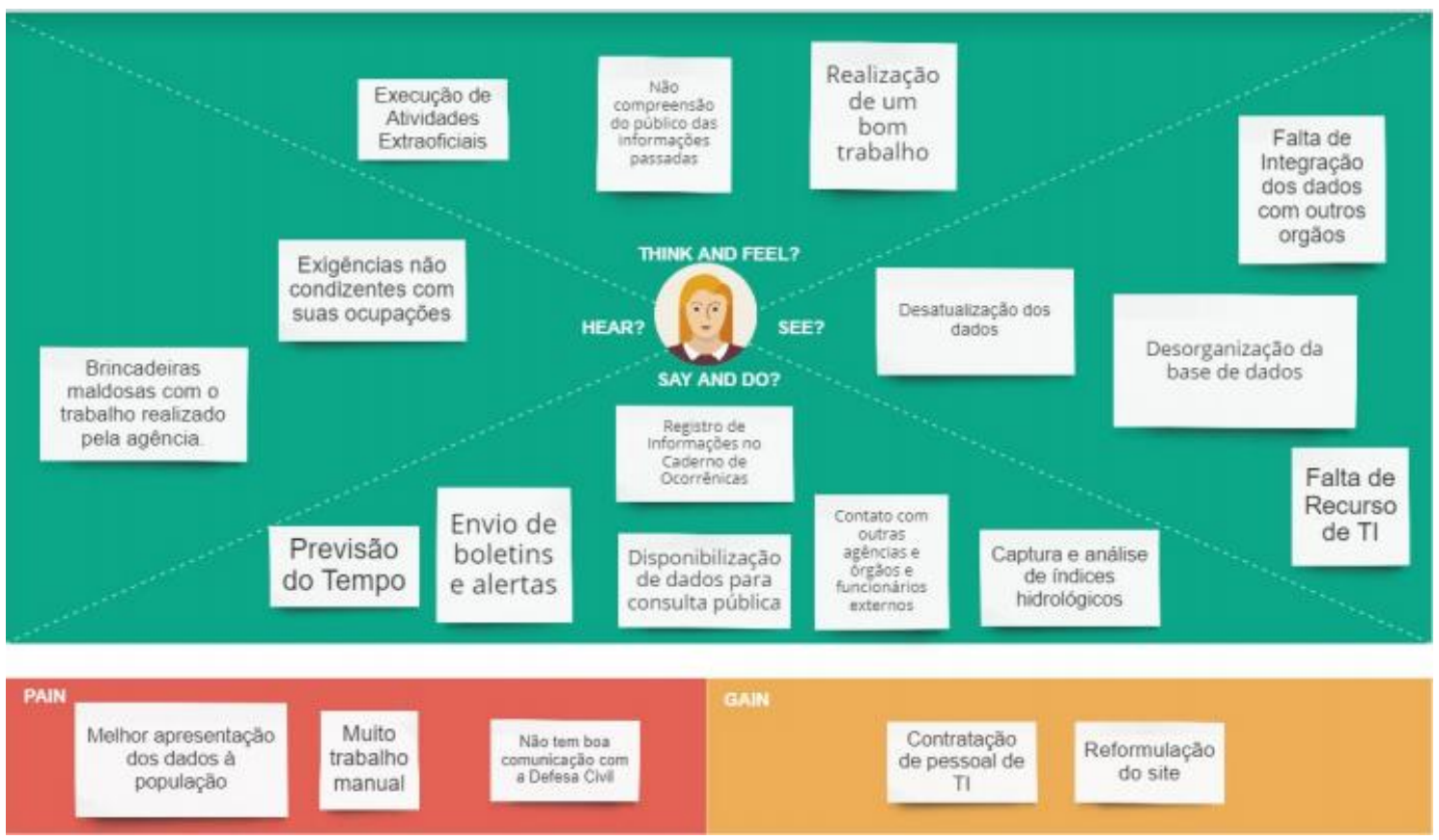

Figura 01. Mapa de Empatia

Em seguida foram realizadas conversas com a equipe da Defesa Civil sobre a interação com a APAC para acesso e uso das informações tempo. As principais descobertas foram descritas em um Mapa Mental (Figura 02), entre as quais: a comunicação entre APAC e Defesa Civil se dá por meios convencionais, como e-mail, telefone e SMS, os quais funcionam bem em situações normais do tempo. Porém, em caso de fortes precipitações, a comunicação precisa ser mais adequada à tomada de decisão. Além disso, é essencial o envolvimento das pessoas para fornecimento de informações em tempo real sobre incidentes naturais em localidades específicas.

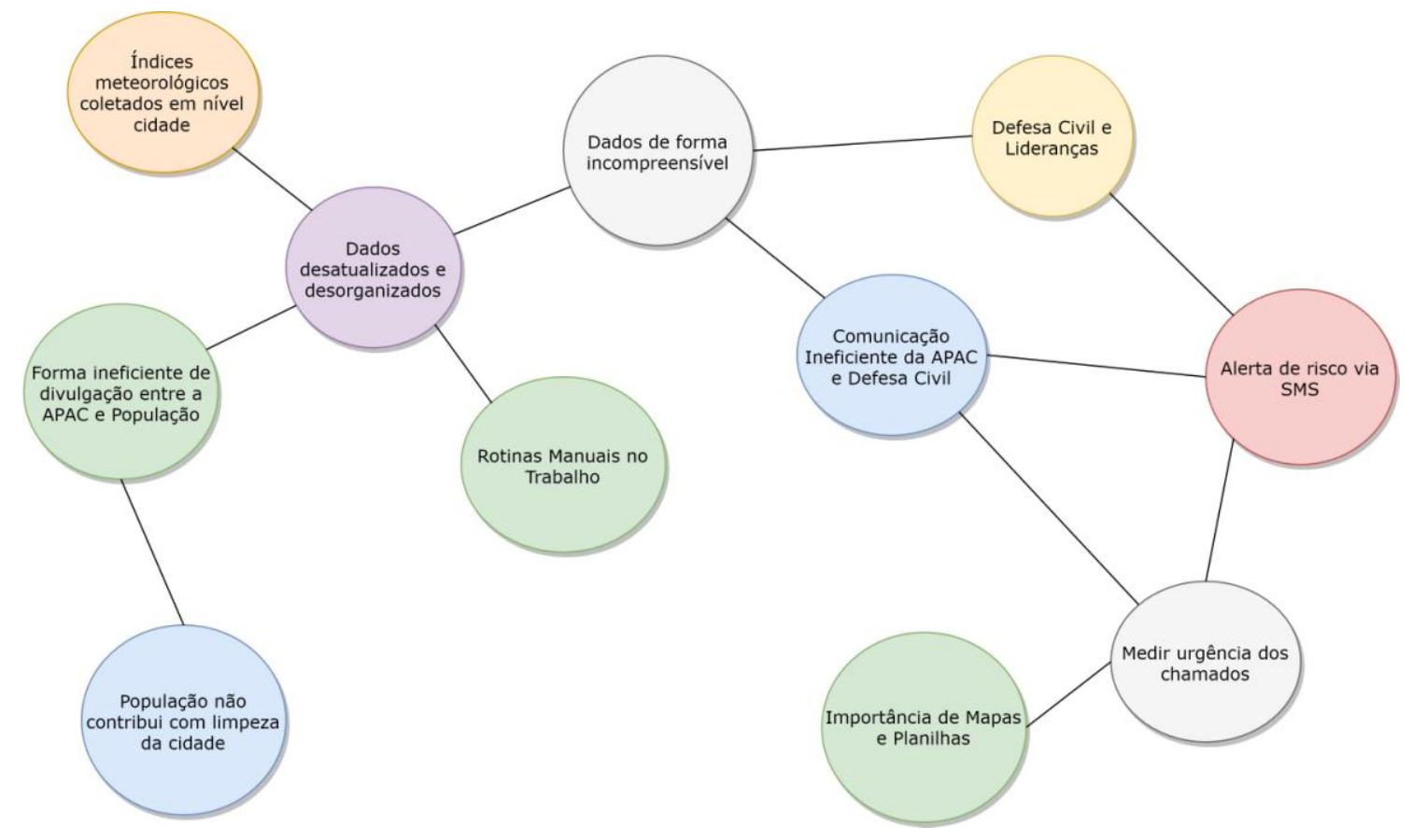

Figura 02. Mapa Mental 


\subsection{Ideação}

A ideação consistiu na geração e refinamento de ideias que poderiam ser aplicadas como solução ao desafio proposto, ou seja, melhorar a comunicação entre APAC e Defesa Civil com envolvimento da população. Essa etapa é inicialmente de caráter divergente, pois tenta produzir uma grande quantidade de ideias e, ao final, de caráter convergente, pois é selecionada a ideia que se apresenta mais promissora.

Inicialmente, foi realizada uma sessão de brainstorming entre a equipe do projeto para responder a seguinte questão: "como poderíamos melhorar a comunicação entre a APAC e a Defesa Civil?". Os participantes foram estimulados a elaborar de uma a cinco respostas que correspondem a ideias livres. Nesta atividade, as ideias são acolhidas sem qualquer impedimento e deve se deixar os preconceitos de lado e buscar aprimorar as ideias alheias. Ao todo foram geradas 14 ideias (Tabela 01).

Em seguida fez-se necessário identificar a ideia mais promissora de acordo com uma avaliação por meio dos seguintes critérios norteadores, selecionados pela equipe do projeto: Participação e Colaboração (PC), enfatiza a colaboração e o engajamento entre os atores envolvidos no processo; Personalização (PE), possibilita que a informação sobre o clima e tempo seja disponibilizada sob demanda para atender as especificidades dos usuários; Custo de Implantação (CI), ideia viável técnica e economicamente; e Tempestividade (TE), as informações do clima e tempo são apresentadas no tempo apropriado e de maneira proativa.

Para auxiliar a identificação da ideia mais promissora, foi elaborada uma Matriz de Posicionamento (Tabela 01) que relaciona o nível de atendimento das ideias aos critérios norteadores, numa escala de 0 (não atende) a 10 (atende plenamente). A ideia mais promissora foi considerada aquela que atingiu a maior pontuação correspondente à somatória do valor do nível de atendimento aos critérios norteadores.

Tabela 01. Matriz de Posicionamento

\begin{tabular}{|l|l|l|l|l|l|}
\hline \multirow{2}{*}{ Ideias } & \multicolumn{3}{|c|}{ Critérios } & \multirow{2}{*}{ Soma } \\
\cline { 2 - 5 } & PC & PE & CI & TE & \\
\hline $\begin{array}{l}\text { Desenvolvimento de um sistema computacional (mobile, } \\
\text { desktop) de compartilhamento de informação entre as duas } \\
\text { organizações }\end{array}$ & 7 & 7 & 5 & 10 & 29 \\
\hline $\begin{array}{l}\text { Criação de um ramal entre a APAC - Defesa Civil - Liderança } \\
\text { (População). }\end{array}$ & 8 & 4 & 9 & 7 & 28 \\
\hline $\begin{array}{l}\text { Funcionário exclusivo em cada uma das entidades para } \\
\text { intermediar a comunicação entre eles. }\end{array}$ & 5 & 8 & 6 & 6 & 25 \\
\hline $\begin{array}{l}\text { Desenvolvimento de um aplicativo mobile para a } \\
\text { comunicação entre as partes e acompanhamento por parte } \\
\text { da população das informações meteorológicas fornecidas } \\
\text { pela a APAC. }\end{array}$ & 8 & 10 & 7 & 8 & 33 \\
\hline $\begin{array}{l}\text { Remodelagem do site da APAC. } \\
\text { Criação de um sistema para o registro e notificação de } \\
\text { ocorrências meteorológicas dos atores. }\end{array}$ & 9 & 7 & 5 & 8 & 29 \\
\hline $\begin{array}{l}\text { Automatizar a inserção de informação na planilha de dados } \\
\text { provindos da ANA (Agência Nacional de Águas). }\end{array}$ & 4 & 3 & 4 & 5 & 16 \\
\hline
\end{tabular}




\begin{tabular}{|l|l|l|l|l|l|}
\hline Automatização do sistema de envio de SMS à Defesa Civil. & 7 & 3 & 9 & 6 & 25 \\
\hline $\begin{array}{l}\text { Estabelecer parcerias com projetos de coleta de índices } \\
\text { meteorológicos em "nível popular" e instalar mais } \\
\text { pluviômetros artesanais pela cidade. }\end{array}$ & 6 & 8 & 6 & 30 \\
\hline Normalizar o banco de dados da APAC. & 0 & 2 & 2 & 0 & 4 \\
\hline $\begin{array}{l}\text { Cruzar dados do grau de área de risco com o local da } \\
\text { ocorrência do chamado e quantificar os chamados. }\end{array}$ & 7 & 5 & 6 & 8 & 26 \\
\hline $\begin{array}{l}\text { Melhorar as interfaces dos mapas para acesso às } \\
\text { informações relevantes pelos técnicos da Defesa Civil. }\end{array}$ & 3 & 10 & 7 & 6 & 26 \\
\hline $\begin{array}{l}\text { Criação de páginas em redes sociais para o envio de de } \\
\text { informações. }\end{array}$ & 8 & 5 & 10 & 9 & 32 \\
\hline $\begin{array}{l}\text { Colaboração e compartilhamento de informações sobre } \\
\text { processo, técnicas e táticas com outros órgãos de Defesas } \\
\text { Civis. }\end{array}$ & 4 & 4 & 5 & 4 & 17 \\
\hline
\end{tabular}

A Ideação prosseguiu com a materialização da ideia mais promissora visando a avaliação desta através de feedback dos atores envolvidos. Inicialmente, foi produzido um Storyboard (Figura 03) que ilustra o aplicativo móvel (APP) como meio de comunicação e compartilhamento de informações do templo e clima entre a APAC, Defesa Civil e População. O Storyboard apresenta como possível cenário o uso de pluviômetros de baixo custo através dos quais a população poderia medir o volume acumulado diário da água da chuva e então registrar através do APP. Esta informação pluviométrica poderia complementar a rede oficial de pluviometria mantida pela APAC.

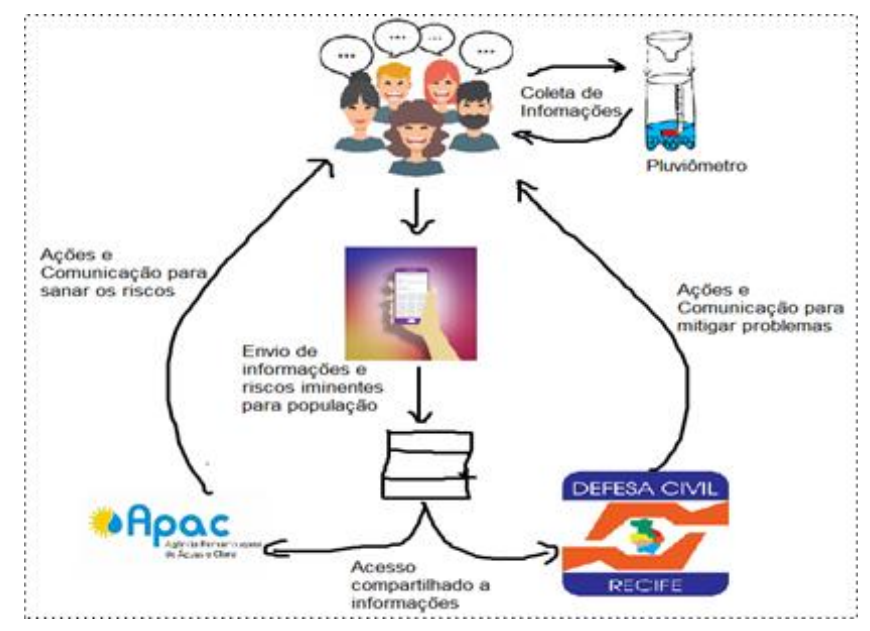

Figura 03. Storyboard

Em seguida foi produzido um Storytelling ${ }^{2}$ usado para contar histórias relevantes através de recursos audiovisuais ${ }^{3}$. O ser humano estabelece ligações interpessoais e emocionais através do ato de contar histórias. Esta ferramenta é útil para convencer os atores envolvidos sobre a importância da solução proposta.

\footnotetext{
2 https://youtu.be/515HaHGDy3U

${ }^{3}$ https://www.powtoon.com/home/
} 
O processo criativo de elaboração de Storytelling ajudou a equipe a identificar propostas de valor por meio de funcionalidades. O software poderia interconectar informações oriundas da APAC (clima e tempo), da Defesa Civil (gestão de incidentes) e dos usuários (registro de incidentes e pluviometria manual) para emissão de alertas em áreas de riscos de maneira proativa. Outra funcionalidade poderia permitir aos usuários enviar informações, em tempo real, sobre as áreas de riscos através de mensagens e fotos, e assim criar um novo canal de interação entre a população e a Defesa Civil.

De modo a tornar as propostas de valor tangíveis, foi produzido um protótipo por meio da ferramenta QuantUX (https://www.quant-ux.com/). A Figura 04 apresenta as interfaces com o usuário (UI) de acesso (lado esquerdo) e de notificação de alertas (lado esquerdo) do APP denominado ALLerta.

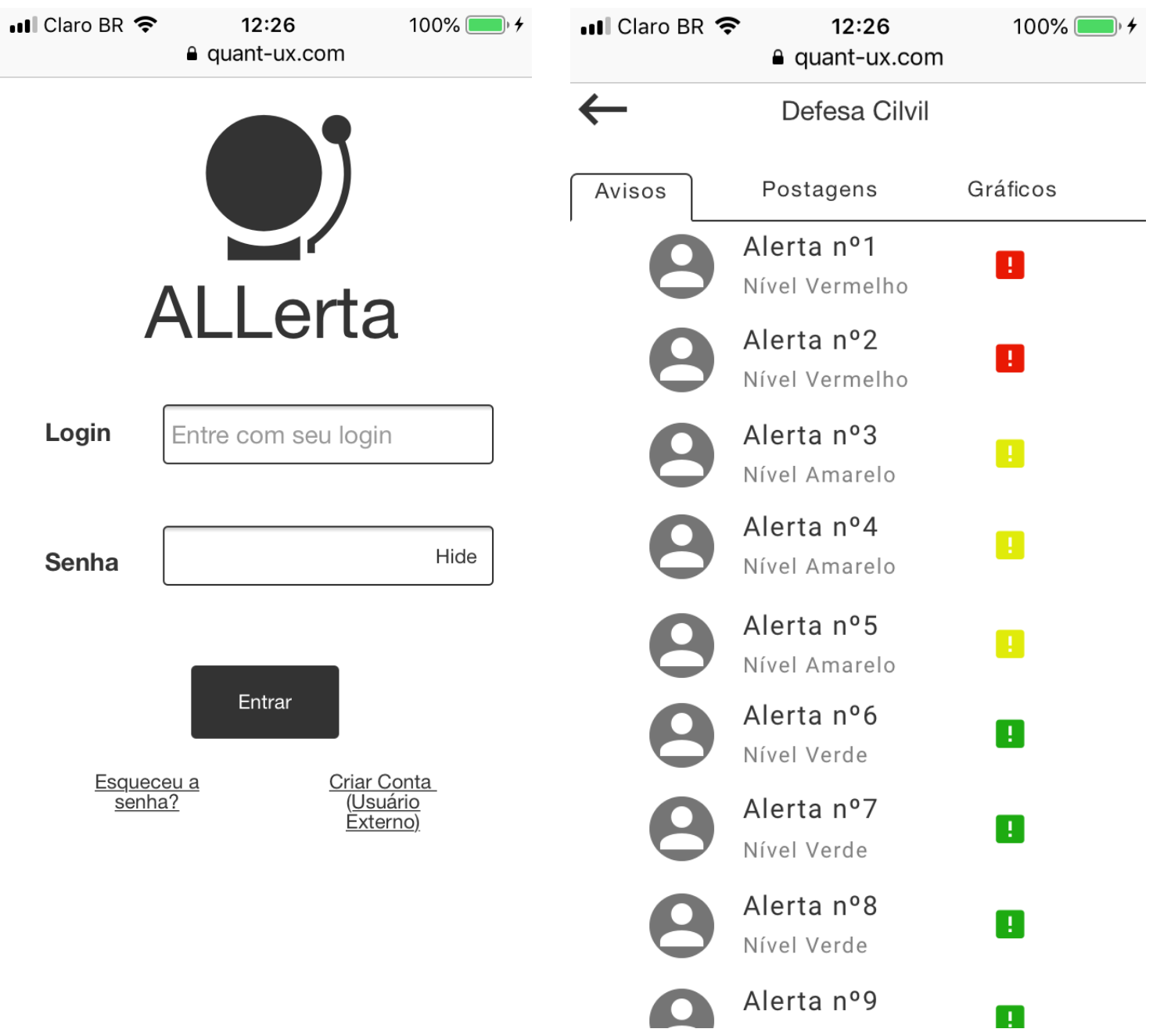

Figura 04. UI do Protótipo

\subsection{Implementação}

A etapa de Implementação teve como objetivo traçar a estratégia para levar a solução ao mercado, por meio da modelagem de um negócio sustentável e da construção de uma versão enxuta da solução proposta. 
O Modelo de Negócios da solução proposta (Figura 05) foi construído por meio da ferramenta Canvas de Modelo de Negócio que permite comunicar a lógica de como o valor será produzido e entregue ao público-alvo.

Em seguida foi produzido o Produto Mínimo Viável (MVP do inglês Minimum Viable Product) da solução. O MVP é uma versão enxuta da solução de software focada em demonstrar a entrega do valor, por meio de funcionalidades-chave:

1. Visualização do nível de precipitação pela Defesa Civil: disponibiliza para a Defesa Civil informações em tempo real sobre o nível de chuva em diversas áreas da cidade. As informações serão coletadas diretamente da base de dados disponibilizadas pela APAC.

2. Criação de alertas para Defesa Civil: a solução terá a capacidade de levantar os dados do tempo e clima disponibilizados pela APAC, fazendo o cruzamento desses dados com as informações coletadas das áreas de riscos disponibilizados pela Defesa Civil. Com o cruzamento das informações a solução notificará antecipadamente a Defesa Civil por meio de alertas as áreas de risco com perigo iminente para a população em uma determinada região.

3. Envio de informações pela população: a solução permitirá que informações das áreas de risco, registradas pela população, sejam compartilhadas com a Defesa Civil. Para verificação da veracidade das informações compartilhadas, a solução identificará a localização do usuário, como também permitirá apenas o compartilhamento de informações com a respectiva imagem da área de risco.

4. Envio de alertas para a população: a solução permitirá que a Defesa Civil repasse alertas mais urgentes para a população interessada.

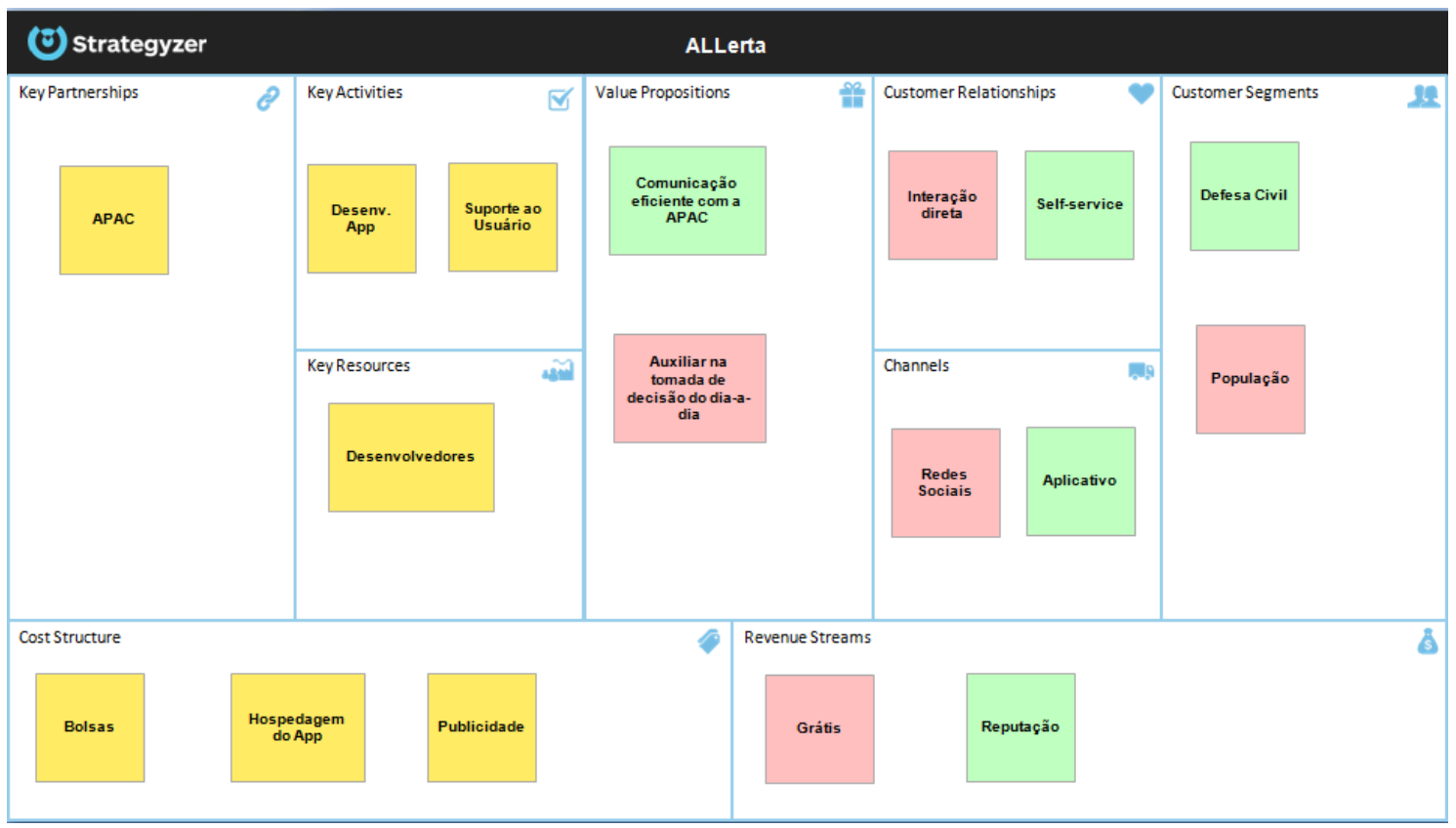

Figura 05. Modelo de Negócios 
A Figura 06 apresenta as UI referentes as funcionalidades 1 (lado direito) e 2 (lado esquerdo) do MVP. Ao final da Implementação, o MVP foi disponibilizado para avaliação por alguns funcionários da Defesa Civil. A Figura 07 apresenta o feedback obtido, cujo resultado foi considerado satisfatório pela equipe do projeto.

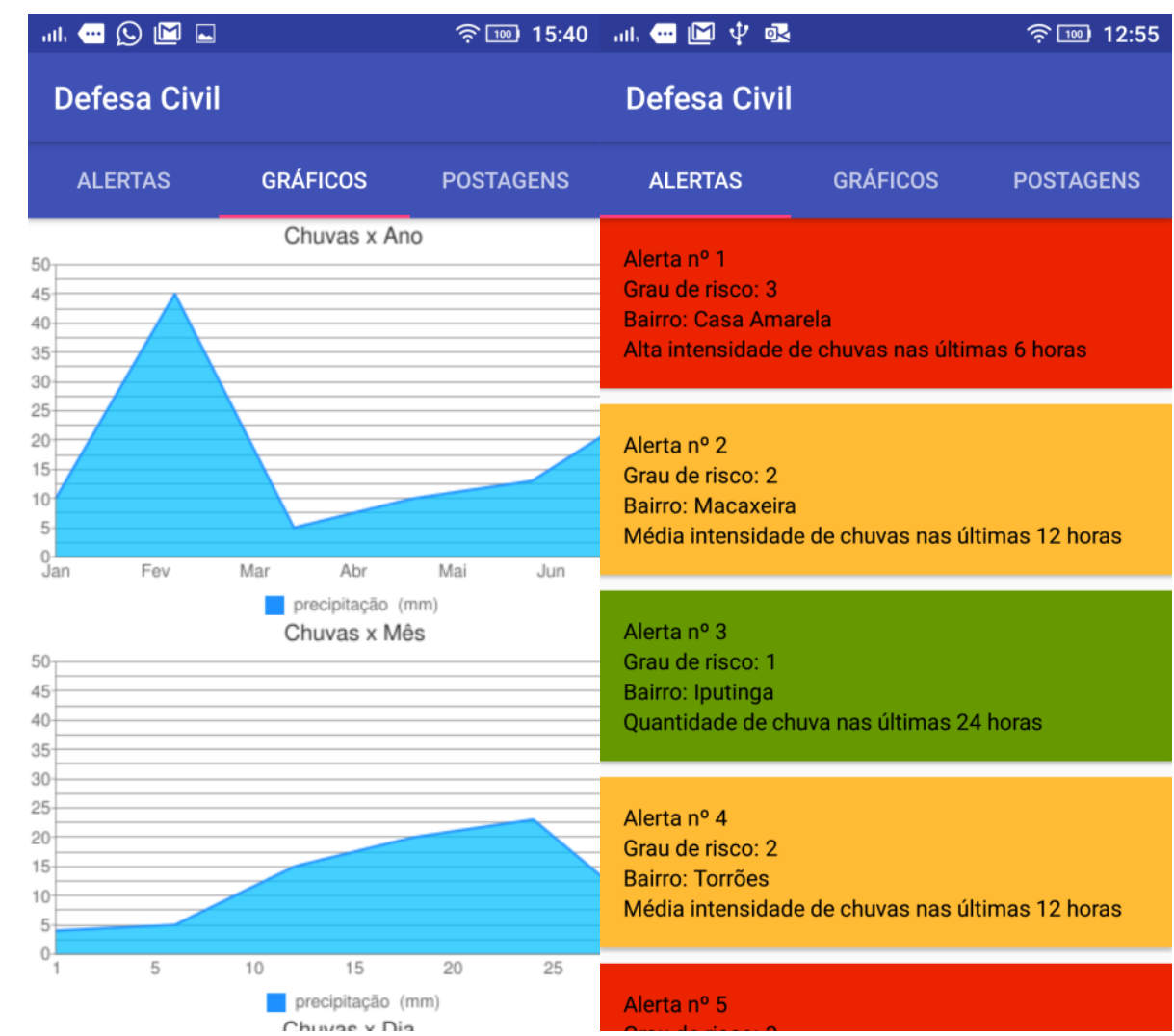

Figura 06. UI do MVP
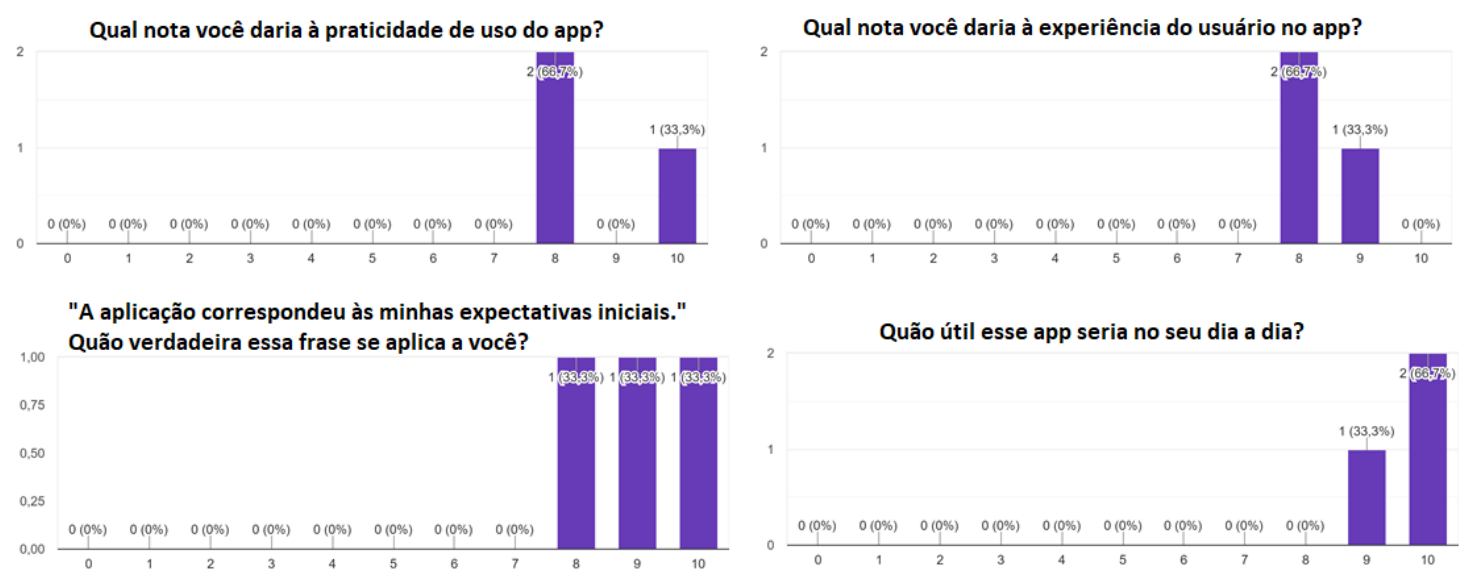

Figura 07. Avaliação do MVP

\section{Considerações finais}

Este trabalho apresenta o relato da experiência da aplicação do processo HCD (HumanCentered Design) para desenvolvimento de uma solução de software. A solução desenvolvida visa ser um meio de comunicação e troca de informações entre: APAC, organização responsável pelo monitoramento e controle de informações do tempo e 
clima do estado de Pernambuco; Defesa Civil do município do Recife, organização responsável por atuar na prevenção e ação no caso de incidentes causados por eventos climáticos; e população em geral, afetada quando da ocorrência de eventos climáticos severos.

A contribuição científica do trabalho consistiu na demonstração que o processo HCD, baseado na criatividade e centrado no humano, pode ser usado com sucesso no desenvolvimento de soluções baseadas em software. Já a contribuição técnica do trabalho consistiu na construção de uma versão enxuta (MVP) da solução de software, a qual foi bem avaliada pela equipe da Defesa Civil.

Como oportunidades de trabalhos futuros, estão: avaliação da aplicação do processo HCD em outros contextos e negócios; construção do produto de software final a ser disponibilizado aos usuários, a partir de incrementos do MVP; e avaliação da entrega de valor pelo produto de software final.

\section{Referência}

Barros, H. R. and Lombardo, M. A. (2013). Zoneamento Climático Urbano da Cidade do Recife: uma contribuição ao planejamento urbano. GeoUSP: Espaço e Tempo (33), p. 186-197.

Christel, I., Hemment, D., Bojovic D., Cucchietti, F., Calvo, L., Stefaner, M. \& Buontempo, C. (2018). Introducing design in the development of effective climate services. Climate Services (9), p. 111-121.

Fukuzimi, S., Natsuco, N. \& Yukiko, T. (2017). How to Apply Human-Centered Design Process (HCDP) to Software Development Process?. IEEE/ACM 1st International Workshop on Design and Innovation in Software Engineering (DISE), p. 13-16.

HCD. (2018). Kit de Ferramentas para Estratégia Centrado no Ser Humano, $2^{\circ}$ Edição. Disponível em http://brazil.enactusglobal.org/wp-content/uploads/sites/2/2017/01/ Field-Guide-to-Human-Centered-Design_IDEOorg_Portuguese-

73079ef0d58c8ba42995722f1463bf4b.pdf. Acessado em: 07 Junho 2018.

Hirata, E., Giannote, M. A., Larocaa, A. P. C. \& Quintanilha, J. A. (2013). Mapeamento dinâmico e colaborativo de alagamentos na cidade de São Paulo. Boletim de Ciências Geodésicas, ISSN 1982-2170, Curitiba, v. 19, n 4, p. 602-623.

Ribeiro, G. C., Oliveira, R. F. F., Alencar, G. A. \& Souza, R. A. C. (2018). Desenvolvimento de um aplicativo de alerta de alagamento utilizando os métodos do toolkit HCD. Boletim do Tempo Presente (12), p. 39-53.

Viríssimo, D. B., Russo, M. C., Ogura, A. T. \& Corsi, A. C. (2014). NIAGRISK: gestão de risco de desastres naturais. In: Workhop de Computação Aplicada à Gestão do Meio Ambiente e Recursos Naturais, Brasília. Anais... 4 p. (Evento ocorrido no 34. Congresso da Sociedade Brasileira de Computação, 2014, Brasília) 